\title{
MONITORAMENTO DO METAL CROMO TOTAL NA BACIA DOS RIOS GARÇAS E ARAGUAIA NA ÁREA URBANA DE BARRA DO GARÇAS/MT: A IMPORTÂNCIA DO CONTEXTO NO PROCESSO DE ALFABETIZAÇÃO CIENTÍFICA
}

\author{
TOTAL CHROMIUM METAL MONITORING IN THE GARÇAS AND ARAGUAIA \\ RIVER BASIN IN THE URBAN AREA OF BARRA DO GARÇAS/MT: THE \\ IMPORTANCE OF CONTEXT IN THE PROCESS OF SCIENTIFIC LITERACY
}

DOI: $\underline{\text { 10.23926/RPD.2526-2149.2020.v5.n3.p1666-1682.id938 }}$

\section{Eduardo Ribeiro Mueller \\ Doutor em Educação em \\ Ciências e Matemática \\ (REAMEC/UFMT) \\ Mestre em Educação \\ (UFMT) \\ Professor na Universidade \\ Federal de Mato Grosso \\ (UFMT/Campus Araguaia) \\ edurmuller@hotmail.com}

Kaique de Oliveira

Graduando em Química

(UFMT/Campus Araguaia)

kkaiquebg@gmail.com

\section{Wagner Batista dos \\ Santos}

Doutor em Ciências com

Habilitação em Química

Inorgânica (UFSCar)

Mestre em Química (UFU)

Professor na Universidade

Federal de Mato Grosso

(UFMT/Campus Araguaia)

wbsantos38@gmail.com
Resumo: Este trabalho é resultado de um projeto desenvolvido nos rios Araguaia e Garças, perímetro urbano da cidade goiana de Aragarças e das mato-grossenses Barra do Garças e Pontal do Araguaia. Nosso objetivo foi delinear o ensino de química a partir de um problema real e local, demonstrando no processo a importância do conhecimento químico na leitura e interpretação de fenômenos provenientes da ação antrópica na natureza. A pesquisa é mista em função da associação de dados quantitativos e qualitativos. Nossos dados advêm das revelações do contexto (rios) e das análises, as quais tiveram como referencial o método NBR 10.739 da Associação Brasileira de Normas Técnicas (ABNT) e da técnica de espectrometria de absorção atômica (EAA). As evidenciações durante, e os relatos após a finalização da pesquisa serviram de base para a constatação da instrumentalização discente, mostrando a importância da apropriação do conhecimento químico e do contexto na alfabetização científica.

Palavras-chave: Contexto de Aprendizagem. Ensino de Química. Alfabetização Científica.

\begin{abstract}
This work is the result of a project developed on the Araguaia and Garças rivers, an urban perimeter of the city of Aragarças in Goias state and Barra do Garças and Pontal do Araguaia in Mato Grosso. Our objective was to outline the teaching of chemistry from a real and local problem, demonstrating in the process the importance of chemical knowledge in the reading and interpretation of phenomena arising from anthropic action in nature. The research is mixed due to the association between quantitative and qualitative data. Our data comes from the context revelations (rivers) and the analyzes, which had as reference the method NBR 10.739 of the Brazilian Association of Technical Standards (ABNT) and the technique of atomic absorption spectrometry (EAA). The evidence during, and the reports after the end of the research, served as a basis for the verification of student instrumentalization, showing the importance of the appropriation of chemical knowledge and of context in scientific literacy.
\end{abstract}

Keywords: Learning Context. Chemistry Teaching. Scientific Literacy. 


\section{INTRODUÇÃO}

Este artigo é resultado de um projeto desenvolvido nos rios Araguaia e Garças, cujos leitos convergem (Garças é afluente) no perímetro urbano da cidade goiana de Aragarças e das mato-grossenses Barra do Garças e Pontal do Araguaia, onde estão localizados dois Campi da UFMT Araguaia.

Nesta região (Vale do Araguaia), os rios Garças e Araguaia são impactados diretamente por fontes pontuais e difusas de poluição devido ao forte desenvolvimento agrícola e pecuarista, e também ao fato de boa parte de sua extensão estar localizada no perímetro urbano das cidades, com exploração direta pelo turismo local. As águas desses dois rios são utilizadas para abastecimento público; a captação de água de Pontal do Araguaia e de Aragarças localiza-se no Araguaia e a captação de Barra do Garças utiliza as águas do Garças.

Figura 1 - Encontro das águas dos rios Garças (a sua direita, ponte menor) e Araguaia. Ao centro, entre os rios, está a cidade de Pontal do Araguaia/MT; à direita Barra do Garças/MT e à sua esquerda Aragarças/GO. O rio Araguaia divide os dois estados nessa regiã

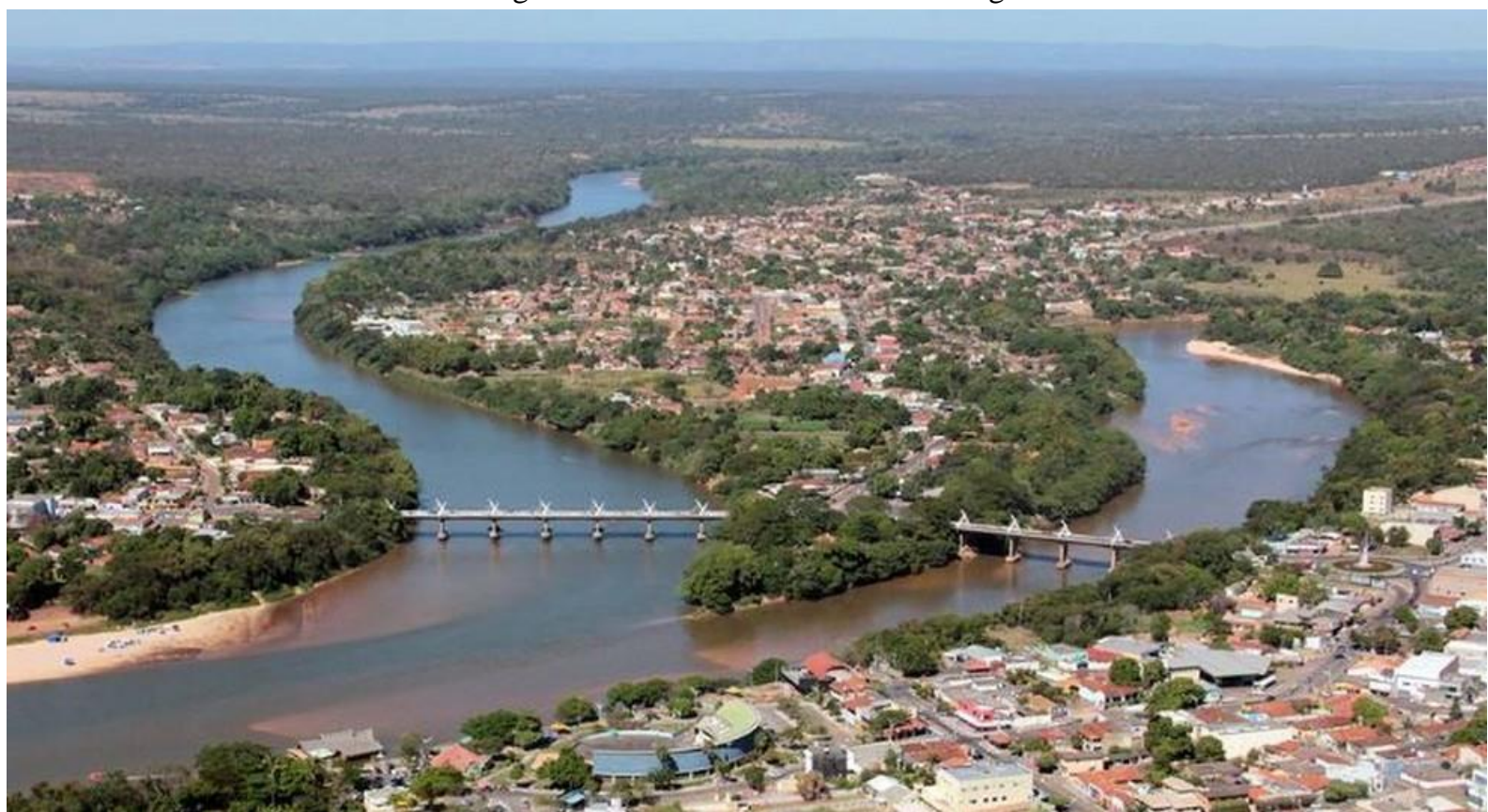

Foto: Prefeitura de Barra do Garças. Disponível em: https://g1.globo.com/mt/mato-

grosso/noticia/2020/07/17/justica-determina-que-barra-do-garcas-e-pontal-do-araguaia-mt-adotem-quarentenaobrigatoria.ghtml. Acesso em 07/12/2020.

$\mathrm{Na}$ escolha da problematização, nosso olhar se voltou à qualidade das águas que abastecem nossas casas. A busca pelo Cromo total, metal altamente tóxico, se deu em função da presença de empresas locais com essa demanda em potencial.

Nosso objetivo foi delinear o ensino de química (análises laboratoriais) a partir de um problema real e local, demonstrando no processo a importância do conhecimento químico na leitura e interpretação de fenômenos provenientes da ação antrópica na natureza. 


\section{REFERENCIAL TEÓRICO}

\subsection{SOBRE A TOXICIDADE DO CROMO (CR) EM ÁGUAS DOCES URBANAS}

De acordo com a NBR 10004 (ABNT, 2004a), todo resíduo é classificado como perigoso quando for inflamável, corrosivo, reativo ou tóxico, como é o caso dos metais pesados (elementos químicos com densidade superior a $4 \mathrm{~g} / \mathrm{cm}^{3}$ ). Apesar de essenciais em alguns sistemas biológicos, grande parte das substâncias que se enquadram nesse grupo são tóxicas aos seres humanos, mesmo em baixa concentração (PAUL, 2017; EDELSTEIN, BEM-HUR, 2018).

Este é o caso do cromo $(\mathrm{Cr})$, um metal muito duro e bastante resistente à ação de agentes atmosféricos, utilizado na fabricação de aços inoxidáveis e outras ligas metálicas, como produto químico para tratamento de madeira, em curtumes no curtimento de couros, e na indústria de materiais refratários (KADIRVELU; THAMARARAISELVI; NAMASIVAYAM, 2001). Um dos principais problemas associados ao uso do cromo é a mobilidade e toxicidade que possui em sua forma hexavalente. Segundo Kobielska et.al. (2018) o cromo (VI) é um dos metais mais alergênicos e o contato direto na pele, inalação ou ingestão pode resultar em reações alérgicas, desenvolvimento de carcinomas e até mesmo levar à morte.

Segundo Resolução CONAMA No 357/2005 (CONAMA, 2005), as águas doces são classificadas em: I - classe especial: águas destinadas: a) ao abastecimento para consumo humano, com desinfecção; b) à preservação do equilíbrio natural das comunidades aquáticas; e c) à preservação dos ambientes aquáticos em unidades de conservação de proteção integral. II - classe 1: águas que podem ser destinadas: a) ao abastecimento para consumo humano, após tratamento simplificado; b) à proteção das comunidades aquáticas; c) à recreação de contato primário, tais como natação, esqui aquático e mergulho (CONAMA, 2000); d) à irrigação de hortaliças que são consumidas cruas e de frutas que se desenvolvam rentes ao solo e que sejam ingeridas cruas sem remoção de película; e e) à proteção das comunidades aquáticas em Terras Indígenas.

Nesta resolução encontramos também os valores de referência para a presença de metais pesados em $\mathrm{mg} / \mathrm{L}$, cujo valor para o cromo total é de $0,05 \mathrm{mg} / \mathrm{L}$; no entanto, o cromo hexavalente constitui uma particularidade em termos de tratamento (CONAMA, 2005). Devido ao fato de não precipitar bem, todos os efluentes contaminados com cromo hexavalente devem ser segregados dos demais para serem encaminhados ao pré-tratamento, que consiste em redução do cromo à forma trivalente. São empregados como agentes redutores o sulfato ferroso ou o metabissulfito de sódio. $\mathrm{O}$ pH da reação é mantido em torno de 2,5 a 3,0 pela adição de 
ácido sulfúrico. Completada a redução, os efluentes poderão sofrer em seguida o processo de precipitação através de elevação de $\mathrm{pH}$ ao valor recomendado. No entanto, os processos de tratamento de água para distribuição à população não utilizam esse procedimento, o que pode ocasionar em um efeito de acúmulo desse metal.

\title{
2.2. SOBRE A IMPORTÂNCIA DOS CONTEXTOS DE APRENDIZAGEM
}

Poderia o conhecimento ser transferido mecanicamente para a cabeça dos alunos? Sugerimos um não a esta resposta, mesmo se sua prática é baseada na tendência liberal tradicional, onde prevalecia/prevalece a transmissão densa e livresca de conteúdos, formando alunos não questionadores, acríticos e passivos (QUEIROZ; MOITA, 2007).

Não que alunos não possam assimilar conceitos mecanicamente, acreditamos nisso! Apenas concordamos que conhecimentos assimilados assim não se estruturam tempo suficiente de modo a serem considerados aprendizagem de fato. $\mathrm{O}$ esquecimento daquilo que foi estudado apenas para passar nas provas ocorre naturalmente, tornando inútil seu estudo (CHASSOT, 1995). O grau máximo de abstração está na nossa capacidade de operacionalizar generalizações (aplicação destes conceitos em diferentes contextos), tornando aquilo que julgamos aprendido um conceito verdadeiro (VIGOSTSKY, 2008). Sem o advento da prática reflexiva e contextual não acreditamos haja formação eficiente, e este trabalho é sobre isso!

As diversas teorias filosóficas sobre compreensão e orientação da prática educacional em diversos momentos e circunstâncias da história humana nos dão uma luz:

\begin{abstract}
a formação humana se constitui numa trama de relações sociais, o que significa dizer que o ser humano emerge no seu modo de ser dentro de um conjunto de relações sociais: as ações, as reações, as condutas normatizadas, ou não, as censuras, as relações de trabalho, de consumo, dentre outras que constituem a prática social e constitui o homem como ser histórico (Queiroz; Moita, 2007, p. 1).
\end{abstract}

Quando consideramos este pressuposto para a educação, ou seja, quando a vemos como prática social e histórica, elevamos seu status quanto à valorização da aprendizagem em relação ao ensino. Em outras palavras, não há aprendizagem capaz de provocar maturação do organismo de modo a desenvolver o sujeito que aprende se esta não estiver condicionada às relações estabelecidas com outros indivíduos em determinado ambiente cultural (VYGOTSKY, 1998).

Para Libâneo (1982), a maioria dos professores provavelmente baseia sua prática em prescrições pedagógicas que viraram senso comum, incorporadas quando da sua passagem pela escola ou transmitidas por colegas mais velhos. Tais condições nos mostram que dar conta da compreensão e orientação da prática educacional em diferentes momentos é uma tarefa complexa (MUELLER; CHASSOT, 2017). 
Acreditamos que a aprendizagem contextual sobrepuja tanto a tentativa de aprendizagem mecânica quanto ao próprio senso comum, este último destacado nas palavras de Libâneo. Figueiredo (2016) nos coloca uma contradição, pois concordamos com ele quando diz: "contexto de aprendizagem é um conjunto coerente de fatos, circunstâncias e pessoas que acompanham e concretizam uma situação de aprendizagem - o que acontece, para e por que acontece, onde acontece, como acontece, quando acontece e a quem acontece" (FIGUEIREDO, 2016, p. 813).

Por outro lado, discordamos dele quanto diz de que aulas tradicionais representam contextos de aprendizagem justamente pelo fato de não haver nelas este lugar de significação do conhecimento. Não há ancoragem de novas informações constituindo novos significados (MOREIRA, 2006), ou mesmo coexistência de significados antigos e novos, como propõe a teoria do perfil conceitual (MORTIMER, 2000) apenas na verbalização oral e escrita do conhecimento entre quatro paredes. Mais importante ainda, se reconhecemos ser a educação uma prática social e histórica, pautá-la na realidade com problematizações ambientais (como é este caso), sociais, políticas, culturais, entre outros, faz-se necessário, sobretudo numa sociedade de classes antagônicas, como no Brasil, para que esta educação não esteja a serviço (apenas) da manutenção da classe dominante. Que ela seja também instrumento de libertação, de preservação, conquistas e garantia de direitos.

\subsection{COMO A ENCULTURAÇÃO NA CIÊNCIA DEPENDE DA ALFABETIZAÇÃO CIENTÍFICA?}

Podemos alocar ao centro desse debate a utilização da ciência na resolução de problemas. Ser útil está intrinsecamente subordinado à ideia de lograr êxito na resolução de problemas, e isso ninguém pode negar que a ciência faça. À medida em que resolve problemas, a ciência assume-se cada vez mais verdadeira, e seus métodos cada vez mais eficientes. Nesse contexto, a própria ciência é desafiada quanto à sua utilidade, dado que ao mesmo tempo que produz riquezas pode gerar mortes, degradação ambiental dentre outros, dialetizando o conceito de utilidade.

Diante de um problema, primeiro necessitamos lê-lo, interpretá-lo. O conhecimento dos conceitos científicos é quem vai possibilitar o olhar mais crítico, a interlocução com o problema.

Se os problemas postos pela prática social possuem solução no corpo de conhecimentos científicos disponíveis, basta instrumentalizar o aprendiz; essa é a dimensão do trabalho pedagógico! Se o problema é um novo enigma, é a instrumentalização anterior que permitirá ao cientista a produção de novos conhecimentos e a resolução de problemas; essa é a dimensão do trabalho do pesquisador e do cientista como especialistas! São momentos diferentes, mas em ambos o conhecimento disponível é a condição para avançar! (SANTOS, 2005, p. 44). 
A (provável) presença de metais pesados tóxicos nas águas de dois rios utilizados para banhos, pesca, abastecimento de estações de tratamento etc. é um problema posto pela prática social na abordagem deste artigo. Como resolvê-lo é uma questão mais crítica da própria prática social, e não representou nossa intenção. Como identificá-lo, sim! E é nesta identificação que percebemos a importância da alfabetização científica.

Importante destacar que os termos 'alfabetização científica' e 'letramento científico' são empregados no Brasil desde a década de 1950 para traduzir a expressão scientific literacy (TEIXEIRA, 2013). Segundo Deboer (2000), scientific literacy envolveria a aquisição de uma herança de conhecimentos produzidos pela humanidade, que habilitaria os indivíduos a entenderem o mundo natural, tornando-os mais informados, capacitando-os a ter experiências mais “inteligentes" no cotidiano (DEBOER, 2000 p. 592).

\begin{abstract}
Com base nessa perspectiva, argumentamos que a expressão scientific literacy estabelece vínculos entre ciência, leitura e escrita, colocando as três em um mesmo patamar de imprescindibilidade. Considerando que leitura e escrita são bens culturais que possibilitam a inserção nas sociedades grafocêntricas e que, também, são, nessas sociedades, habilidades cujo domínio é relevante para todos os indivíduos, interpretamos que a expressão scientific literacy transmite a ideia de que aprender ciências deveria ser algo tão imprescindível quanto aprender a leitura e a escrita, uma apropriação desejável para todos os seres humanos, a ser estabelecida como um fenômeno de massa (TEIXEIRA, 2013, p. 801).
\end{abstract}

Chassot (2003) defende, ao escrever sobre alfabetização científica como possibilidade de inclusão social, "que a ciência seja uma linguagem; assim, ser alfabetizado cientificamente é saber ler a linguagem em que está escrita a natureza. É um analfabeto científico aquele incapaz de uma leitura do universo" (CHASSOT, 2003, p. 91). A ideia associada ao 'ler' denota interpretação de fenômenos naturais a luz da ciência, elevando o olhar a um nível mais crítico, fora do senso comum.

É este o sentido da alfabetização científica que defendemos houve neste trabalho, pois à medida que as coletas e análises foram requisitando leituras e interpretações por parte do aluno, este mesmo adquiriu condições de elucidar o fenômeno de contaminação das águas dos rios. Hoje, um ano e meio depois, este mesmo aluno participou densamente da escrita deste artigo. Sua memória ao relatar as coletas e as análises se mostraram praticamente intactas, sugerindo-nos a eficiência de sua aprendizagem no processo, em outras palavras, de sua alfabetização científica.

\title{
3 Metodologia
}

Considerando que todo problema de pesquisa requisita, no contexto da investigação, uma escolha metodológica, buscamos na literatura específica aquela que melhor representaria 
o nosso trabalho e, pela característica de abordagem quanto aos dados elegemos nossa pesquisa como mista, com enfoque que combina os aspectos qualitativo e quantitativo. Creswell (2007) explica o contexto que requisita a pesquisa mista.

\begin{abstract}
Esses procedimentos se desenvolveram em resposta à necessidade de esclarecer o objetivo de reunir dados quantitativos e qualitativos em um único estudo (ou em um programa de estudo). Com a inclusão de métodos múltiplos de dados e formas múltiplas de análise, a complexidade desses projetos exige procedimentos mais explícitos. Esses procedimentos também foram desenvolvidos, em parte, para atender a necessidade de ajudar os pesquisadores a criar projetos compreensíveis a partir de dados e análises complexas (CRESWELL, 2007, p. 211).
\end{abstract}

A estrutura que orientou o estudo adotou critérios quantitativos, evidenciados nas coletas e análises, e qualitativos, por meio dos quais se analisa a influência do contexto na alfabetização científica do estudante envolvido no projeto, coautor neste artigo. Na perspectiva das ciências humanas, elucidar a realidade e, quando possível transformá-la, enseja preocupação maior se comparado ao tipo de dados que classifica a pesquisa. Se fosse essa a nossa intenção (transformação da realidade) o status qualitativo da pesquisa aumentaria em relação aos dados quantitativos que desvelam a realidade. Ser mista, no entanto, é uma classificação que traduz melhor a complexidade do trato com os dados quali-quantitativos que manejamos aqui.

\title{
3.1. Procedimentos Metodológicos
}

Como o contexto pode assistir estudantes de modo a qualificar a construção do conhecimento por eles empreendido? A resposta a esta questão corrobora com a escolha dos rios como lugar de problematização, dada a acessibilidade física e cognitiva que os estudantes locais possuem a estes patrimônios naturais. Ainda, é significativa a preocupação de nossos estudantes e professores com fenômenos verificados empiricamente nesses rios, como liberação de esgoto, assoreamento, exploração comercial das margens praieiras durante o festival de praia etc.

Neste projeto, a ideia foi mostrar como a química é relevante no desenvolvimento de procedimentos de monitoramento de metais pesados, como o Cromo, interligando os rios (contexto natural) e o laboratório (contexto de análise), produzindo alfabetização científica no estudante envolvido. Dois momentos pautaram o percurso metodológico: a coleta e a análise. Derivam deles nossas reflexões acerca da construção do conhecimento por parte do aluno. Destacamos a seguir os procedimentos e materiais envolvidos na coleta e análise. 


\subsubsection{Coleta}

A coleta se deu em 2019 em 3 pontos dos rios, a primeira no período chuvoso, no dia 01 de março, e a segunda no período da seca, no dia 11 de junho. Os três pontos têm localização no perímetro urbano dos municípios de Barra do Garças/MT, Pontal do Araguaia/MT e Aragarças/GO.

Nas duas datas as amostras foram coletadas em frascos de plástico e de vidro, sendo os mesmos preenchidos submersos, fechados, transportados e armazenados sob resfriamento em uma caixa isotérmica, posteriormente encaminhado ao Laboratório de Pesquisa em Ciência dos Materiais - LEMat, da Universidade Federal de Mato Grosso/Campus do Araguaia. A escolha dos pontos de amostragem se deu nas imediações da estação de coleta de água (rio Garças), lançamento de efluentes industriais (rio Garças) e confluência entre os rios Garças e Araguaia (rio Araguaia). Os 3 pontos escolhidos sofrem de influência antrópica direta, e foram escolhidos por nós pela proximidade de empresas aos rios e pela relevância direta à saúde das pessoas (caso da estação de captação de água). São eles:

- Ponto 01: Empresa de Tratamento e Corte de Couros - Barra do Garças/MT;

- Ponto 02: Estação de Captação de Água de Barra do Garças/MT;

- Ponto 03: Empresa de abate e corte de carne bovina - Barra do Garças/MT.

Os materiais utilizados na coleta foram:

- Caixa Isotérmica;

- Termômetro Digital à prova de água;

- Frascos de plástico/vidro;

- Pipeta Pasteur;

- Solução ácida $\left(\mathrm{HNO}_{3}\right)$ para conservação da amostra

\subsubsection{ANÁLISE}

A análise se utilizou da técnica de espectrometria de absorção atômica (EAA), uma das técnicas analíticas mais empregadas em análises dessa natureza, de custo relativamente baixo e com resultados de simples interpretação.

A espectrometria de absorção atômica (EAA) é uma técnica analítica relativamente seletiva, muito utilizada nas análises de elementos metálicos nas mais diversas matrizes, e sua sensibilidade a torna particularmente útil na análise de amostras ambientais, contendo um feixe de luz proveniente de uma lâmpada construída a partir do elemento que se pretende analisar. 
A técnica exige que o feixe de luz seja dirigido através de uma nuvem do elemento atomizado em uma chama ou cubeta do forno de grafite, passando por um monocromador até atingir o detector, pois a quantidade de energia absorvida no comprimento de onda específico é diretamente proporcional à concentração do elemento na amostra, obedecendo-se a Lei de Lambert-Beer.

Segundo Galo e Colombo (2009) a Lei de Lambert-Beer estabelece uma relação linear entre a absorvância e a concentração da amostra. Na representação gráfica, esta relação consiste em um eixo coordenado chamado de curva de calibração ou curva analítica, tendo uma obtenção de medidas na faixa de absorvância entre 0 a 1 , cumprindo igualmente em sistemas multicomponentes.

Os materiais utilizados na análise foram:

- Espectrometria de Absorção Atômica (EAA);

- Chapa de Aquecimento;

- $\quad$ Becker de $50 \mathrm{~mL}$;

- Funil;

- Balança Analítica;

- Pipeta Graduada de 10mL;

- Pêra;

\section{Resultados}

\subsection{O CONTEXTO NATURAL COMO ESPAÇO DE APRENDIZAGEM DURANTE A COLETA}

A coleta contribuiu com nossa alfabetização científica à medida que evidenciou nuances do próprio contexto, desvelando a realidade ao nosso olhar, e à medida que nos proporcionou aplicação de um método, por meio do qual as amostras foram conservadas e suas informações iniciais extraídas. 
Durante a cheia (mês de março), pudemos observar, dentre outras coisas, o alto índice de matéria orgânica no leito dos rios, pontos de ausência de mata ciliar, degradação de margens em função da ausência de vegetação, turbidez elevada da água, perigos da navegação em época de chuva, elevada quantidade de iguanas em margem urbana, e despejo de esgotos por parte de hotéis e indústrias. As Figuras 2 e 3 ilustram imagem desse momento.

Figuras 2 e 3 - Professores envolvidos na primeira coleta

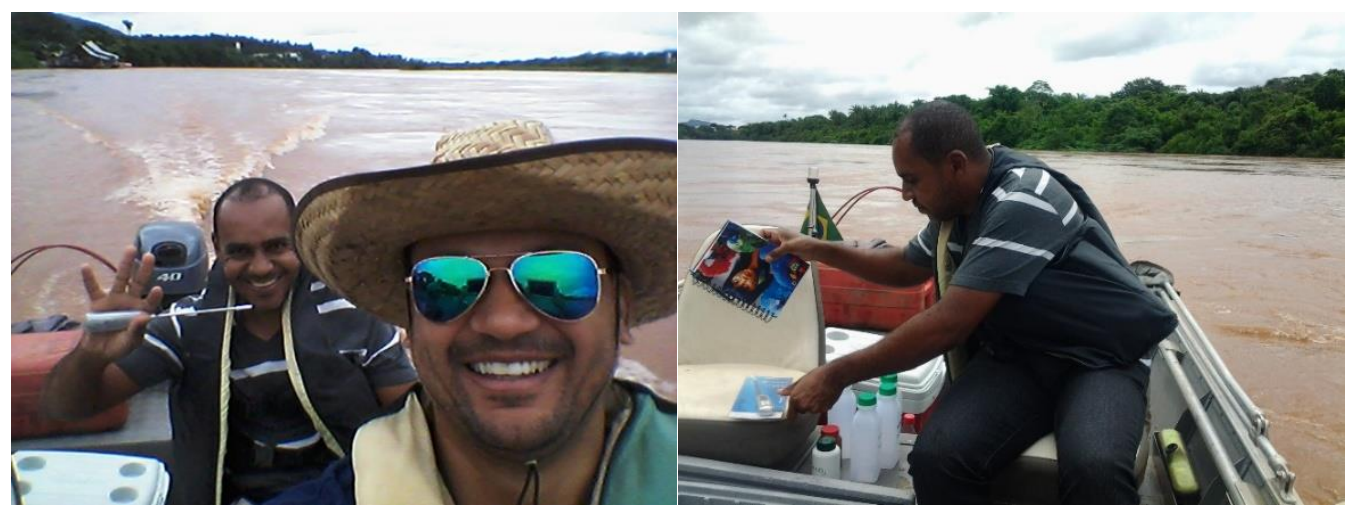

Fotos: Próprio Autor.

Durante a seca (junho) os procedimentos de coleta foram feitos pelo estudante, acompanhado de um dos professores. Não permitimos sua participação na primeira coleta por questões de segurança. Nessa ocasião, constatamos diversos impactos relacionados à presença antrópica: recolhemos diversas redes provenientes de pesca predatória, verificamos o alto índice de assoreamento dos nossos rios (bancos de areia no próprio leito e longas praias), encontramos uma iguana morta em função de ter se prendido a uma das redes que recolhemos, e constatamos que a navegação na época da seca exige experiência em função dos muitos obstáculos presentes no rio (areia e pedras). A seguir imagens da segunda coleta (Figuras 4 a 7). 
Figuras 4 a 7 - Momentos que ilustram a coleta durante a baixa das águas (mês de junho) com participação do aluno envolvido no projeto

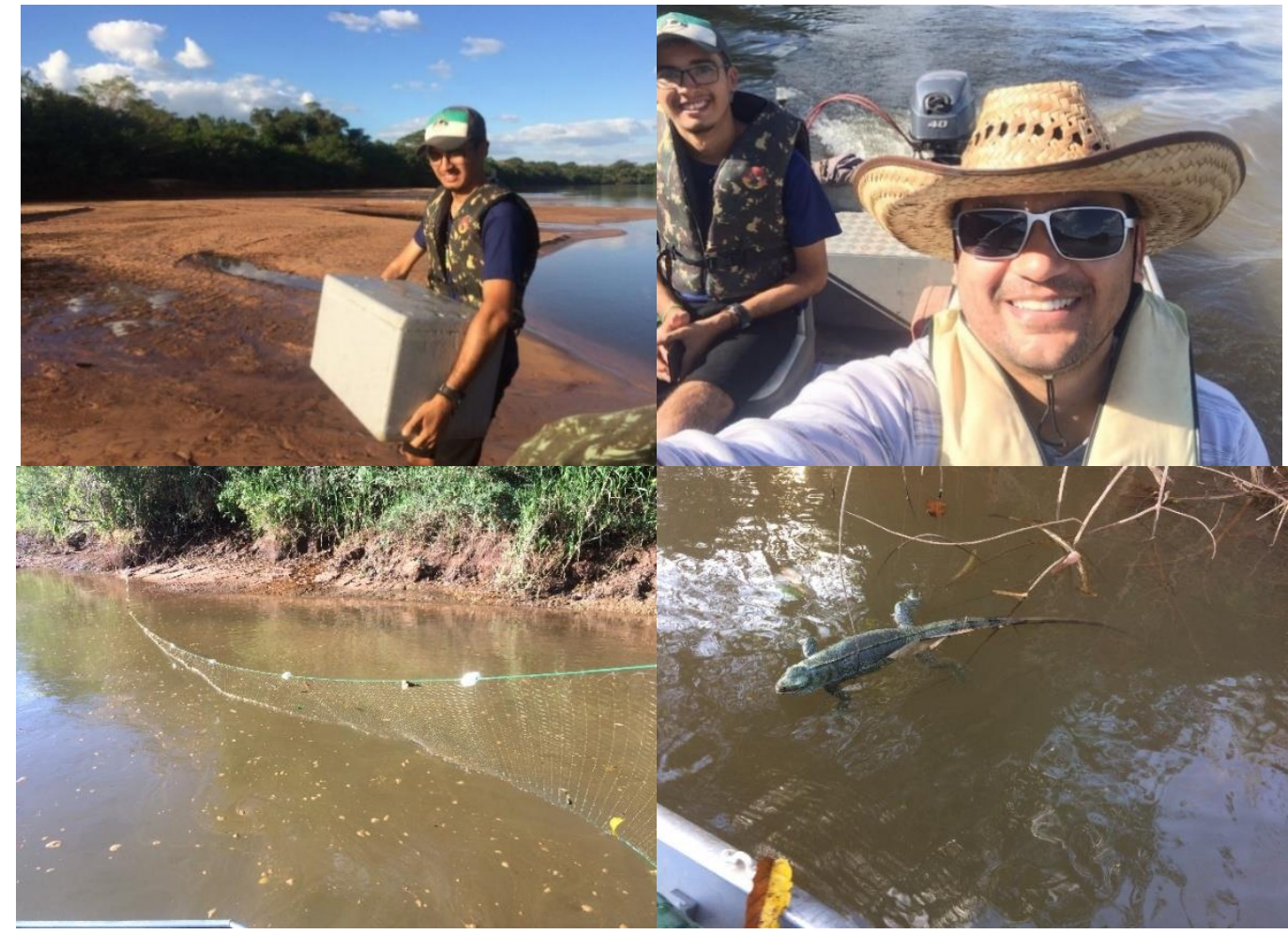

Fotos: Próprio autor

Entre os conhecimentos requisitados pelo método empregado na coleta destacamos: utilização de luvas e máscara, imersão total do frasco na água, aferição de parâmetros de pH e turbidez da água imediatamente colhida, aferição de temperatura da água com termômetro digital, adição de ácido nítrico a uma das amostras colhidas a fim de se atingir $\mathrm{pH}=2$ antes do armazenamento, leitura de coordenadas em Sistema de Posicionamento Global (GPS) e cuidados no armazenamento de modo a preservar todas as amostras em caixa térmica com gelo. Os resultados apresentamos a seguir nas Tabelas 1 e 2 .

\begin{tabular}{cccccc}
\multicolumn{7}{c}{ Tabela 1 - dados da primeira coleta (período chuvoso) } \\
\hline Ponto & $\mathbf{p H}$ & Temperatura & Latitude & Longitude & Horário \\
\hline 01 & 5.0 & $26,5^{\circ} \mathrm{C}$ & $15^{\circ} 53.090^{\prime} \mathrm{S}$ & $052^{\circ} 22.567^{\prime} \mathrm{O}$ & $10 \mathrm{~h} 25 \mathrm{~min}$. \\
02 & 5.0 & $25,5^{\circ} \mathrm{C}$ & $15^{\circ} 54.112^{\prime} \mathrm{S}$ & $052^{\circ} 16.588^{\prime} \mathrm{O}$ & $11 \mathrm{~h} 00 \mathrm{~min}$. \\
03 & 5.0 & $25,5^{\circ} \mathrm{C}$ & $15^{\circ} 53.427^{\prime} \mathrm{S}$ & $052^{\circ} 14.000^{\prime} \mathrm{O}$ & $11 \mathrm{~h} 27 \mathrm{~min}$. \\
\hline
\end{tabular}

Fonte: Autores 
Tabela 2 - Dados da segunda coleta (período de seca)

\begin{tabular}{cccccc}
\hline Ponto & $\mathbf{p H}$ & Temperatura & Latitude & Longitude & Horário \\
\hline 01 & 5.0 & $22^{\circ} \mathrm{C}$ & $15^{\circ} 53.129^{\prime} \mathrm{S}$ & $052^{\circ} 22.530^{\prime} \mathrm{O}$ & $16 \mathrm{~h} 40 \mathrm{~min}$. \\
02 & 6.0 & $25^{\circ} \mathrm{C}$ & $15^{\circ} 54.114^{\prime} \mathrm{S}$ & $052^{\circ} 16.592^{\prime} \mathrm{O}$ & $15 \mathrm{~h} 27 \mathrm{~min}$. \\
03 & 5.0 & $25^{\circ} \mathrm{C}$ & $15^{\circ} 53.343^{\prime} \mathrm{S}$ & $052^{\circ} 14.434^{\prime} \mathrm{O}$ & $17 \mathrm{~h} 35 \mathrm{~min}$. \\
\hline
\end{tabular}

Fonte: Autores

Nas Tabelas 1 e 2 é possível observar os pontos de amostragem utilizados para o desenvolvimento da pesquisa no período chuvoso e da seca. Os dados colhidos e técnicas utilizadas tem como base o método preconizado pela NBR 10.739 da Associação Brasileira de Normas Técnicas (ABNT).

Segundo a resolução CONAMA 357/2005, a condição ideal de pH em águas de rios corresponde a valores numa faixa de 6 a 9. Como foi possível observar nas tabelas 1 e 2, apenas um dos pontos apresentou valor de $\mathrm{pH}$ dentro da faixa aceitável. Na maioria dos pontos verificamos valor de predominância ácida, $\mathrm{pH}=5,00$, tanto no período chuvoso quanto no período seco. As temperaturas não tiveram variação significativa, exceto no ponto 1 da coleta de junho (tabela 2), onde incidia sombra de árvores e provavelmente profundidade maior. Todos esses dados servem de parâmetro para avaliação de contra provas e para informações inerentes às análises.

Este conjunto de informações caracteriza a contribuição do contexto no processo de alfabetização científica. Deriva delas a possibilidade de percepção, por parte do aluno, da aplicação de conteúdos/conceitos ora estudados em sala de aula e laboratório. Corrobora também na enculturação do estudante em causas de relevância socioambientais à medida que exige dele sensibilizar-se com elas, movendo-o em direção a sua cidadania, permitindo-o fazer a associação do conhecimento científico com a resolução de problemas. Não menos importante, empodera sua capacidade de ler e interpretar todos esses fenômenos naturais (CHASSOT, 2003).

\subsection{O LABORATÓRIO COMO ESPAÇO DE APRENDIZAGEM DURANTE AS ANÁLISES}

No Laboratório de Pesquisa em Ciência dos Materiais - LEMat as análises foram realizadas valorizando os saberes inerentes aos procedimentos técnicos exigidos pelos laboratórios de química, e valorizando a construção do conhecimento do aluno, que ao tempo de cada procedimento desenvolvia relevante interlocução com os resultados produzidos. Apresentamos a seguir duas sequências com descrições dos procedimentos elaborados pelo próprio aluno, a primeira onde relata o trabalho envolvido na precipitação e remoção do ferro 
na amostra e a segunda na identificação das concentrações de Cromo total utilizando a absorção atômica.

Sequência 1: trabalho desenvolvido e relatado pelo próprio aluno na precipitação e remoção do ferro na amostra colhida para análise de outros elementos metálicos

\begin{abstract}
Após cada coleta, encaminhamos o material ao Laboratório de Pesquisa em Ciência dos Materiais - LEMat da Universidade Federal de Mato Grosso/Campus do Araguaia. Uma vez lá, extraiu-se uma pequena amostra, adicionou-se ao Becker de $250 \mathrm{~mL}$ e alocou-se em uma chapa de aquecimento, temperatura de $225^{\circ} \mathrm{C}$, até chegar numa redução de $50 \mathrm{~mL}$ por evaporação.
\end{abstract}

Após este procedimento, pesou-se 40,4382 gramas de Hidróxido de sódio P.A lentilhas $(\mathrm{NaOH})$ para preparação de uma solução de Hidróxido de sódio $(\mathrm{NaOH})$ $40 \%$. Em seguida, mediu-se o $\mathrm{pH}$, tendo um resultado igual a 14 (Básico), levou-se ao banho de gelo para um processo exotérmico e etiquetou-se em um recipiente de vidro.

A amostra inicial da água, proveniente da coleta em estoque, que continha um volume de $50 \mathrm{~mL}$, foi reduzida novamente, por aquecimento, a um volume de $20 \mathrm{~mL}$, e teve seu $\mathrm{pH}$ novamente medido. Em seguida, foram adicionados hidróxido de sódio, inicialmente solução à $40 \%$ e depois hidróxido de sódio sólido (Lentilhas), para que ocorresse a precipitação do íon metálico, principalmente o ferro na forma de hidróxido $\left(\mathrm{Fe}(\mathrm{OH})_{2}\right.$ e $\mathrm{Fe}(\mathrm{OH})_{3}$. Como poderíamos ter a presença das duas formas de íons ferro $\left(\mathrm{Fe}^{+2}\right.$ e $\left.\mathrm{Fe}^{+3}\right)$ adicionou-se dez gotas de peróxido de hidrogênio $\left(\mathrm{H}_{2} \mathrm{O}_{2}\right)$ para que os metais que apresentavam um estado de oxidação menor sofressem um processo de oxidação, gerando uma única espécie.

A solução resultante foi filtrada a vácuo e separada para a posterior determinação espectroscópica na região do UV-Vis, da presença de cromo. A uma pequena alíquota desta solução acrescentou-se cinco gotas da solução Tiocianato de Potássio (KSCN) 0,5 mol. $\mathrm{L}^{-1}$, não se observando alteração na coloração da solução (amarelo claro), indicando a ausência de íons ferro na solução. À solução de estoque, sem tratamento, proveniente da coleta, adicionou-se também algumas gotas de Tiocianato de Potássio (KSCN) 0,5 mol. $\mathrm{L}^{-1}$, sendo observada a presença de uma coloração vermelha intensa indicando a presença do íon Ferro (II/III).

Na sequência 1 a descrição do processo evidencia o quanto o aluno se apoderou do processo de análise. No relato é possível verificar que o trato dado à escrita tem plenas condições de representar sua aprendizagem em química, pois dela deriva domínio da linguagem química em relação a importantes conceitos, tais como: concentração, potencial hidrogeniônico e potencial hidroxiliônico; identificação, nomeação e representação de substâncias; manuseio de massas, temperaturas e volumes; íons, oxidação e redução, relevância das mudanças de cores na identificação de precipitados etc.

Quando inserido num contexto de aprendizagem, esta interlocução com o conhecimento químico encontra o seu lugar social, posicionando a ciência, o fazer ciência, na própria prática social (SANTOS, 2005). Apresentamos a seguir a sequência 2. 
Sequência 2: trabalho desenvolvido e relatado pelo próprio aluno na obtenção das concentrações das amostras de Cromo

Para determinação da concentração de cromo na amostra de água utilizou-se o equipamento de Espectrometria de Absorção Atômica (EAA), que identifica elementos em baixas concentrações, podendo-se associar ao sistema de análise em fluxo e permitindo estudos de especiação.

Para a curva de calibração, foram preparadas soluções estoque $100 \mathrm{mg} \mathrm{L}^{-1}$ de cromo: preparadas por diluição das soluções padrão $1000 \mathrm{mg} \mathrm{L}^{-1}$. Foram transferidos $5 \mathrm{~mL}$ das soluções padrão $1000 \mathrm{mg} \mathrm{L}^{-1}$ para balões de $50 \mathrm{~mL}$ e completou-se o volume com água deionizada. As amostras de água foram coletadas em garrafas plásticas transparentes de 2 litros descontaminadas em banho de ácido nítrico $10 \%$ (v/v) por um período de 24 horas e lavados várias vezes com água deionizada. No laboratório as amostras de água foram refrigeradas à aproximadamente $4{ }^{\circ} \mathrm{C}$ até o momento da análise. A coleta, acondicionamento e preservação das amostras foram feitas de acordo com Nogueira \& Souza (2005).

Na preparação da amostra de água no equipamento detectou-se que a média de absorbância vs concentração $(\mathrm{mg} / \mathrm{L})$ gera uma curva padrão linear, um indicativo de cromo total. Esta curva serve de parâmetro para a determinação da concentração das amostras. Os resultados encontrados foram:

Amostra do Ponto 01: 1,69 x10 $0^{-5} \mathrm{~mol} / \mathrm{L}(0,0045 \mathrm{mg} / \mathrm{L})$;

Amostra do Ponto 02: $1,81 \times 10^{-5} \mathrm{~mol} / \mathrm{L}(0,0017 \mathrm{mg} / \mathrm{L}$;

Amostra do Ponto 03: $1,88 \times 10^{-5} \mathrm{~mol} / \mathrm{L}(0,0026 \mathrm{mg} / \mathrm{L})$.

Não é possível determinar a exatidão do aparecimento deste contaminante em função da extensão da Bacia do Araguaia, que percorre várias cidades e regiões agrícolas. Os resultados também mostram a presença de cromo total, cuja toxicidade depende de seu estado de oxidação, sendo o Cr (VI) mais tóxico que o Cr (III), distinção essa não abordada neste estudo. A detecção da presença deste íon nas amostras de água indica que a necessidade de monitoramento da saúde do rio se torna essencial, pois são eles que abastecem nossas casas.

Da mesma forma, a sequência 2 apresenta elementos cognitivos relevantes à nossa percepção em relação a aprendizagem do aluno. Destacamos aqui o manuseio da Espectrometria de Absorção Atômica na obtenção da curva de calibração do Cromo total e na obtenção das concentrações de Cromo nas amostras analisadas. Há, ao final da sequência 2, um retorno do aluno ao contexto! Este chamamento ao local de coleta, trazendo agora uma preocupação estruturada por estudos científicos (necessidade de monitoramento da saúde dos rios) constitui importante resultado alcançado pelo processo educacional. Há nele, minimamente, aspectos de alfabetização científica, de envolvimento social e de cidadania.

\section{CONSIDERAÇõES FinAIS}

Tanto os relatos como a própria experiência (na coleta e nas análises) sugerem uma relevante interlocução do aluno com o conhecimento técnico e com os contextos inerentes ao projeto, sobretudo o contexto ambiental, em que fatos vivenciados revelam a necessidade de ações efetivas para conservação dos rios. Nas palavras de Santos (2005), é da dimensão do 
trabalho pedagógico utilizar os conhecimentos científicos para tentar solucionar os problemas postos pela prática social instrumentalizando o aprendiz.

Para nós, o agravante maior a afetar diretamente a qualidade das águas é a ocupação urbano-industrial nas proximidades do percurso hídrico, principalmente no que condiz ao lançamento de efluentes domésticos e industriais nos rios. Verificamos também, no contexto, eventos que sugerem falta de educação com o meio ambiente e crime ambiental por parte de moradores locais.

De todos os pontos analisados, os que se mostraram mais críticos foram os pontos $1 \mathrm{e}$ 3, próximos, respectivamente, à empresa de Tratamento e Corte de Couros e empresa de abate e corte de carne bovina. Contudo, dados como $\mathrm{pH}$ abaixo dos padrões estipulados pela legislação brasileira (praticamente em todos os pontos) sugerem um potencial de autodepuração do curso hídrico em análise. Investigar as causas dessas alterações é importante e necessária para que novas ações sejam balizadas em prol da manutenção desse importante ecossistema aquático.

Consideramos, por fim, que as análises dos três pontos de amostragem representam indicativo de contaminação suficiente para que autoridades competentes designem ações de monitoramento de modo a preservar a vida humana e a vida aquática potencialmente atingidas.

\section{REFERÊNCIAS}

BRASIL. Resolução CONAMA no 357/2005, de 17 de março de 2005. Dispõe sobre a classificação dos corpos de água e diretrizes ambientais para o seu enquadramento, bem como estabelece as condições e padrões de lançamento de efluentes, e dá outras providências. Disponível em: http://www.mma.gov.br/port/conama/res/res05/res35705.pdf . Acesso em 17/10/2019.

BRASIL. Resolução CONAMA n 20/1986, de 18 de junho de 1986. Dispõe sobre a classificação das águas doces, salobras e salinas do Território Nacional. Diário Oficial da União, 30 de julho de 1986. Disponível em:

http://www2.mma.gov.br/port/conama/res/res86/res2086.html . Acesso em 17/10/2019.

BRASIL. Resolução CONAMA n 274, 29 de novembro de 2000. Dispõe sobre licenciamento ambiental; competência da União, Estados e Municípios; listagem de atividades sujeitas ao licenciamento; Estudos Ambientais, Estudo de Impacto Ambiental e Relatório de Impacto Ambiental." Diário Oficial [da] República Federativa do Brasil (2000). Disponível em: http://www2.mma.gov.br/port/conama/legiabre.cfm?codlegi=272 . Acesso em 17/10/2019.

CHASSOT, Attico Inácio. Para que(m) é útil o ensino? Alternativas para um ensino (de Química) mais crítico. Canoas: Ed. Ulbra, 1995.

CRESWELL, John W. Projeto de pesquisa: métodos qualitativo, quantitativo e misto. tradução Luciana de Oliveira da Rocha. 2. ed. - Porto Alegre: Artmed, 2007. 
DEBOER. George E. Scientific literacy: another look at its historical and contemporary meanings and its relationship to science education reform. Journal of Research in Science Teaching. Vol. 37, n. 6, p. 582-601, 2000. Disponível em:

https://web.nmsu.edu/ susanbro/eced440/docs/scientific_literacy_another_look.pdf. Acesso em: $27 / 10 / 2020$.

EDELSTEIN, Menahem; BEM-HUR, Meni. Heavy metals and metalloids: Sources, risks and strategies to reduce their accumulation in horticultural criops. Scientia Horticulturae. V. 234, p. 431-444, abr. 2018. Disponível em: https://www.sciencedirect.com/science/article/abs/pii/S0304423817307628. Acesso em $17 / 10 / 2019$.

FIGEIREDO, António Dias. A pedagogia dos contextos de aprendizagem. Revista eCurriculum, São Paulo, v. 14, n. 03, p. 809 - 836, jul./set. 2016. Disponível em: https://revistas.pucsp.br/curriculum/article/view/28989. Acesso em 27/10/2020.

GALO, André Luiz; COLOMBO, Marcio Francisco. Espectrofotometria de longo caminho óptico em espectrofotômetro de duplo-feixe convencional: uma alternativa simples para investigações de amostras com densidade óptica muito baixa. Química Nova, v. 33, p. 488-492, jan. 2009. Disponível em: https://www.scielo.br/pdf/qn/v32n2/v32n2a36.pdf. Acesso em 27/10/2019.

KOBIELSKA, Paulina A. et al. Metal-organic frameworks for heavy metal removal from water. Coordination Chemistry Reviews. v. 358, p. 92-107, mar. 2018. Disponível em: https://www.sciencedirect.com/science/article/abs/pii/S0010854517305131. Acesso em 27/10/2019.

LIBÂNEO, José Carlos. Tendências Pedagógicas na Prática Escolar. Revista da Ande, $n^{\circ}$ 6, 1982. Disponível em:

https://praxistecnologica.files.wordpress.com/2014/08/tendencias_pedagogicas_libaneo.pdf. Acesso em 28/10/2020.

MOREIRA, Marco Antônio. A teoria da Aprendizagem Significativa e sua implementação em sala de aula. Brasília: Ed. Universidade de Brasília, 2006.

MORTIMER, Eduardo Fleury. Linguagem e formação de conceitos no ensino de ciências. Belo Horizonte: Ed. UFMG, 2000.

MUELLER, Eduardo Ribeiro. CHASSOT, ATTICO INÁCIO. A Prática de Ensino em Química como Prática Social classificada por meio de Tendências Pedagógicas. Latin American Journal of Science Education. Vol. 4, n 2, Nov. 2017. Disponível em: http://www.lajse.org/nov17/22078_Mueller_2017.pdf. Acesso em 28/10/2020.

NBR 10004 - Caracterização e os tipos de resíduos. Rio de Janeiro, 2004.

NOGUEIRA, Ana Rita de Araújo; SOUZA, Gilberto Batista. Manual de laboratórios: solo, água, nutrição vegetal, nutrição animal e alimentos. Embrapa Pecuária Sudeste. São Carlos-SP, 2005. 334p. 
PAUL, Dipak. Research on heavy metal pollution of river Ganga: A review. Annals of Agrarian Science, v.15, p. 278-286, jun. 2017. Disponível em: https://www.sciencedirect.com/science/article/pii/S1512188716301142. Acesso em 27/10/2019.

QUEIROZ, Cecília Alves Pontes de; MOITA, Filomena Maria Gonçalves da Silva Cordeiro. Fundamentos Sócio-filosóficos da educação: As tendências pedagógicas e seus pressupostos. Campina Grande; Natal: UEPB/UFRN, 2007. Disponível em: http://www.ead.uepb.edu.br/ava/arquivos/cursos/geografia/fundamentos_socio_filosoficos_da _educacao/Fasciculo_09.pdf. Acesso em 28/10/2020.

SANTOS. César Sátiro dos. Ensino de Ciências: Abordagem Histórico-Crítica. Campinas, SP: Armazém do Ipê (Autores Associados), 2005.

TEIXEIRA, Francimar Martins. Alfabetização científica: questões para reflexão. Ciênc. Educ., Bauru, v. 19, n. 4, p. 795-809, 2013. Disponível em: https://www.scielo.br/pdf/ciedu/v19n4/v19n4a02.pdf. Acesso em 27/10/2020.

VYGOTSKY, Lev Semenovitch. A formação social da mente: o desenvolvimento dos processos psicológicos superiores. $6^{\mathrm{a}}$ ed. São Paulo: Martins Fontes, 1998.

VIGOTSKI, Lev Semenovitch. Pensamento e Linguagem. $4^{\text {a }}$ ed. São Paulo: Martins Fontes, 2008.

Recebido em: 3 de outubro de 2020.

Aprovado em: 7 de dezembro de 2020. 